\title{
EDITORIAL
}

\section{Developmental cascades}

\author{
ANN S. MASTEN ${ }^{a}$ AND DANTE CICCHETTI ${ }^{a, b}$ \\ ${ }^{a}$ University of Minnesota; and ${ }^{b}$ Mt. Hope Family Center, University of Rochester
}

There is a long history of interest in developmental theory and research in the processes by which function in one domain or level or system influences another system or level of function over time to shape the course of ontogenesis and epigenesis. Theoretically, these effects reflect the processes (transactions; coactions) by which interactions influence development in complex living systems (Ford \& Lerner, 1992; Gottlieb, 1998, 2007; Sameroff, 2000; Thelen \& Smith, 1998; Ward, 1995). Developmental cascades refer to the cumulative consequences for development of the many interactions and transactions occurring in developing systems that result in spreading effects across levels, among domains at the same level, and across different systems or generations. Theoretically these effects may be direct and unidirectional, direct and bidirectional, or indirect through various pathways, but the consequences are not transient: developmental cascades alter the course of development. Such effects have gone by different names in the literature, including chain reactions, and snowball, amplification, spillover or progressive effects, as well as developmental cascades (Burt et al., 2008; Cicchetti \& Cannon, 1999; Cicchetti \& Tucker, 1994; Dodge et al., 2009; Dodge \& Pettit, 2003; Fry \& Hale, 1996; Hanson \& Gottesman, 2007; Hinshaw, 1992; Hinshaw \& Anderson, 1996; Kagan, 2005; Masten \& Coatsworth, 1998; Masten et al., 2005; Patterson, Reid, \& Dishion, 1992; Rutter, 1999; Rutter, Kim-Cohen, \& Maughan, 2006; Rutter \& Sroufe, 2000).

The articles in this two-part Special Issue of Development and Psychopathology examine cumulative or progressive effects across levels and areas of function in development that have implications for adaptive behavior. At the same time, these papers illustrate diverse methods for testing developmental cascade models of change.

Our work on this Special Issue and the editorial were partially supported by National Science Foundation Grant 0745643 (to A.S.M.) and National Institute of Drug Abuse Grants DA 12903 and DA 17741 and the Spunk Fund, Inc. (to D.C.).

Address correspondence and reprint requests to: Ann S. Masten or Dante Cicchetti, Institute of Child Development, University of Minnesota, 51 East River Road, Minneapolis, MN 55455.
In developmental psychopathology, there has been keen interest in the possibility that adaptive and maladaptive functions and behaviors spread over time to promote or undermine development because of the profound implications for causal theory, prevention, and treatment (Cicchetti, 2002a; Cicchetti \& Curtis, 2006; Masten, Burt, \& Coatsworth, 2006). Cascade effects could explain why some problems in childhood predict widespread difficulties in adulthood, whereas others do not. In their classic review of longitudinal data on adjustment, Kohlberg, LaCrosse, and Ricks (1972) observed decades ago that some indicators of childhood success or problems consistently forecasted adult adjustment across multiple domains of outcome. In particular, they noted the robust and broad predictive validity of general cognitive competence (often indexed by academic achievement or intellectual ability) and socialized conduct versus antisocial behavior (often indexed by persistent rule-breaking behavior). Cascade effects also offer a possible explanation for some of the comorbidity that is observed so often for some disorders, such as conduct disorder (Angold, Costello, \& Erkanli, 1999; Caron \& Rutter, 1991; Jensen, 2003).

Given effects that spread over time for some kinds of psychopathology, well-timed and targeted interventions could interrupt negative or promote positive cascades; these efforts may work by counteracting negative cascades, by targeting the reduction of problems in domains that often cascade to cause other problems, or by targeting improvements in competence in domains that increase the probability of better function in other domains (Cicchetti \& Curtis, 2006; Cicchetti \& Gunnar, 2008; Masten et al., 2006; Masten, Long, Kuo, McCormick, \& Desjardins, 2009). Moreover, if developmental cascades are common and often begin with adaptive behavior in early childhood, then it would explain why the evidence in prevention science indicates a higher return on investment in early childhood interventions, such as high quality preschool programs (Heckman, 2006; Reynolds \& Temple, 2006).

Intervention designs that target mediating processes for change represent cascade models. The "theory of the intervention" represents a hypothesis that the intervention will change the mediating process that will in turn change the out- 
come of the person in key adaptive domains. In other words, the intervention is designed to initiate change in the form of a cascade from the intervention to the mediator to the outcome (Cicchetti \& Hinshaw, 2002; Hinshaw, 2002).

Cascade effects encompass a broad array of phenomena studied in developmental science within and across multiple levels of function, from the molecular level to the macrolevel. Cascade models may account for the pathways by which gene-environment interplay unfolds over time in epigenesis to shape development, linking genes to neural levels of function to behavior to social experience, through processes of multilevel dynamics (Cicchetti, 2002a; Cicchetti \& Cannon, 1999; Gottlieb, 1998, 2007; Hanson \& Gottesman, 2007). These cascades may flow downward across levels, upward, or across domains of function in a developing system and its interactions with other systems as development proceeds. The effects of pharmacological interventions on behavior can be viewed as intentional efforts to induce an upward cascade by means of neurochemical changes that influence neural function in the brain and subsequently adaptive behavior (Charney, 2004; Cicchetti \& Curtis, 2007). The processes by which genetic disorders result in the development of behavioral anomalies have been described as cascades (e.g., Järvinen-Pasley et al., 2008). Biological embedding of experience, as might happen when traumatic or negative experiences alter gene expression or the stress-response systems of a developing child, may begin as a downward cascade (experience alters functional systems in the child) and then subsequently these altered systems may have cascading upward consequences for brain development, stress reactivity, and symptoms of psychopathology through a complex sequence of processes (Cicchetti, 2002b; Cicchetti \& Cannon, 1999; Gunnar \& Quevedo, 2007; Lupien et al., 2006; McEwen \& Stellar, 1993; Meaney, 2010; Shonkoff, Boyce, \& McEwen, 2009). Deterioration in marital relationships has been described as cascades to divorce (Gottman, 1993). Contagion effects observed in social networks of peers or treatment effects that spread in families also can be viewed as cascade effects (Dishion \& Patterson, 2006). Intergenerational transmission of behavior (mediated by genes, experience, and their interplay) or risk can also be viewed as cascade effects linking multiple generations and multiple behaviors or levels of analysis (Meaney, 2010). Research on the intergenerational transmission of parenting (e.g., Belsky, Conger, \& Capaldi, 2009; Conger, Neppl, Kim, \& Scaramella, 2003; Shaffer, Burt, Obradovic, Herbers, \& Masten, 2009) or psychosocial risk (Serbin \& Karp, 2004) offer examples of generation to generation cascades.

Developmental cascades may be positive or negative in their consequences with respect to adaptive behavior. Developmental theories about competence (see Masten et al., 2006) invoke cascades in the fundamental assertion that effectiveness in one domain of competence in one period of life becomes the scaffold on which later competence in newly emerging domains develop: in other words, competence begets competence. Success in early developmental tasks of childhood are expected to foster competence in subsequent and later emerging developmental tasks (Cicchetti \& Schneider-Rosen, 1986; Cicchetti \& Tucker, 1994; Masten \& Coatsworth, 1998; Masten \& Wright, 2009; Sroufe, 1979). This idea also has been described in terms of positive chain reactions (Rutter, 1999) and skill formation (Heckman, 2006). Cognitive scientists have described a variety of cascade processes where an early advantage or disadvantage in one cognitive domain influences another later developing and high order domain. Fry and Hale (1996) examined the influence of increasing speak of information processing on working memory, which in turn, was associated with improvements in fluid intelligence. Indirect connections linking early infant behaviors to later intellectual function have been observed in developmental research (e.g., Bornstein et al., 2006; Colombo et al., 2004).

Developmental models of competence also explicitly or implicitly propose that failures in key developmental task domains have important consequences for psychological well being or function in other domains (Masten et al., 2006). One of the most important cascade models of this kind was proposed by Patterson and colleagues at the Oregon Social Learning Center in the "dual failure" model, which is based on their developmental theory of antisocial behavior (Capaldi, 1992; Patterson, DeBaryshe, \& Ramsey, 1989; Patterson et al., 1992). In this cascade model, behavior problems arising in the family prior to the school years in relation to inept parenting are carried forward into the school context by the child, leading to problems in two new domains of academic and social competence at school. Failures in these two domains of adaptive behavior were expected to contribute in turn to depressive affect. Rejection by normative peers also raised the risk for drifting into relationships with deviant peers who would reinforce further antisocial behavior. Dual cascade models of this kind have been supported in empirical work from the Oregon Social Learning Center (e.g., Capaldi, 1992; Capaldi \& Stoolmiller, 1999; Patterson \& Stoolmiller, 1991), as well as in recent analyses from the Fast Track study (Dodge, Greenberg, Malone, \& the Conduct Problems Prevention Research Group, 2008) and Project Competence (Obradović, Burt, \& Masten, 2010). Cole (1990, 1991; Cole, Martin, Powers, \& Truglio, 1996) proposed and tested a similar competency-based model of depression wherein cumulative effects of academic and social incompetence contributed to depressive symptoms.

The cascading consequences of conduct problems for subsequent school success, social competence, and internalizing problems appear to be one of the most widely corroborated patterns in the literature on developmental cascades to date, and articles in these Special Issues contribute additional supportive evidence. Although this general sequence is supported in different prospective studies, beginning in preschool and later, the timing of assessments that are conducted and cascades that are observed varies across studies. It is conceivable that these cumulative cascade effects continue over an extended age span beginning in the preschool years and 
extending across the years into adolescence. Nonetheless, it will be important for intervention and prevention efforts to understand more precisely when and how the processes underlying the externalizing problem cascade initiate and accelerate and, concomitantly, when the processes that undermine academic or social competence begin to have lasting consequences for the future. Cascade timing has important implications for when it makes most developmental sense to implement preventive interventions (Masten et al., 2009).

Research and classification of mental health disorders also have focused attention on the potential consequences of symptoms for adaptive behavior (Masten et al., 2006). Symptoms of psychopathology are hypothesized to undermine function in important domains of adaptive behavior. Evidence is compelling that symptoms predict impairment in adaptive function, and the criteria defining mental disorders often encompass impairment criteria. However, it is not easy to establish the direct and indirect pathways by which impairment occurs or whether the association of symptoms and impairment is the result of common risks, one problem causing the other, or an artifact of confounded measurement (Masten et al., 2006).

From a methodological standpoint, cascade models are challenging to test for several reasons. Testing cascade models requires longitudinal data that are often difficult and time consuming to collect. Strong tests of cascade models also require repeated assessment of multiple domains or levels of function over time, and the application of complex statistical approaches. The most stringent tests of cascade models have similar requirements to those for testing mediating effects (Cole \& Maxwell, 2006; Masten et al., 2005). It is important to control for the continuity or stability over time that one would expect within most any domain of adaptive behavior. At the same time, it is important to control for the covariance of key measures assessed in the same time frame during an assessment window. If continuity and covariance are not controlled, then it is difficult to establish whether there is a unique and cumulative cascade effect from one domain to another over time and when this might be occurring. Without accounting for within time covariance and across time stability, an apparent cascade effect may reflect correlations that were already present at the beginning of the assessments or that represent an artifact of unmeasured outcome covariance. In effect, the role of within-time correlation and also acrosstime stability are controlled in the most informative designs.

A related challenge for research on developmental cascades occurs when a model to be tested includes newly emerging domains of function or organization. In developmental task theory, for example, the domains of work and romantic competence emerge in adolescence in many developed nations, and subsequently become salient tasks of adulthood (Roisman, Masten, Coatsworth, \& Tellegen, 2004). These emerging tasks are believed to have roots in academic and social competence earlier in childhood; success in earlier tasks builds the skills for success in these later tasks. Therefore, cascades might be expected from success (or failure) in age-salient domains of childhood competence to these newly emerging domains in adolescence. In the situation of emerging domains of behavior like these, or newly developing levels of function (e.g., higher level cognitive skills), it may be difficult to differentiate a cascade effect from developmental manifestations of progress within a broader underlying domain of function or the development of a higher order of organization in a system.

There are other challenges as well. If the assessment windows are close together in time, then the cumulative direction of effects may be lost in the directionally indeterminate covariance within an assessment wave. In other words, a directional cascade effect could be obscured by close waves of data collection that result in high correlations among variables at each assessment wave, with the result that no cascades are evident. In this situation, omitting data or waves to allow more time to elapse between assessment intervals may result in the emergence of a cascade effect across time and domains. Generally, it is important to consider the issue of the interval between assessments and the effect under investigation. The design must allow adequate time for the effects of interest to be manifested (Cole, 2006; Cole \& Maxwell, 2003).

It is also important to remember that correlations within time are consistent with cascade influences, even though the direction(s) of effect cannot be tested with clarity. Thus, given three variables that show high stability over three waves of assessment and that are also intercorrelated within each wave, even in the absence of cross-domain cascade effects, the correlations across the domains may nonetheless increase over time as a result of bidirectional or unidirectional cascade effects occurring among the variables within the time frame of each assessment wave.

In addition, even with powerful statistical model testing of cascade effects in longitudinal designs, there still may be many alternative explanations for observed cascade effects and it is not possible to establish causal effects. Some studies in these Special Issues test alternative models or replicate earlier studies, two compelling approaches for building a convincing evidence base for cascade effects. Some also test potential "third cause variables" that might explain what appears to be a cascade effect. Considering plausible third variable causes is another effective strategy for strengthening the evidence that a cascade effect reflects a causal process linking two aspects of function, rather than an artifact. Nonetheless, the most convincing evidence of a cascade effect will be built on experiments with random assignment to intervention that are designed to produce a particular cascade sequence.

The articles in these Special Issues highlight the range of developmental cascade models and methods under investigation in developmental psychopathology, although as a group these papers emphasize behavioral levels of analysis. Fewer articles test cascades across level, linking context to behavior or behavior to neural or biologic function. Most of the work represented in these Special Issues has focused on naturally occurring cascades rather than experiments to induce cas- 
cades; however, prevention studies are represented among the contributions to the Issues. There is intriguing convergence across some of the findings, although clearly these articles represent the initial stages of rigorous testing of cascade models. As a collective, the articles in these Special Issues represent a highly promising foundation for future research on cas- cades in developmental science. Developmental cascade research has the potential to inform, test, and refine theories of change that are integral to understanding pathways of adaptation, maladaptation, psychopathology, and resilience. Such knowledge is central to the goal of designing preventive interventions with strategic timing and targets.

\section{References}

Angold, A., Costello, E. J., \& Erkanli, A. (1999). Comorbidity. Journal of Child Psychology and Psychiatry, 40, 57-87.

Belsky, J., Conger, R., \& Capaldi, D. M. (2009). The intergenerational transmission of parenting: Introduction to the special section. Developmental Psychology, 45, 1201-1204.

Bornstein, M. H., Hahn, C.-H., Belll, C., Haynes, O. M., Slater, A., Golding, J., et al. Stability in cognition across early childhood: A developmental cascade. Psychological Science, 17, 151-158.

Burt, K. B., Obradović, J., Long, J. D., \& Masten, A. S. (2008). The interplay of social competence and psychopathology over 20 years: Testing transactional and cascade models. Child Development, 79, 359-374.

Capaldi, D. M. (1992). Co-occurrence of conduct problems and depressive symptoms in early adolescent boys: II. A 2-year follow-up at grade 8. Development and Psychopathology, 4, 125-144.

Capaldi, D. M., \& Stoolmiller, M. (1999). Co-occurrence of conduct problems and depressive symptoms in early adolescent boys: III. Prediction to young-adult adjustment. Development and Psychopathology, 11, 59-84.

Caron, C., \& Rutter, M. (1991). Comorbidity in child psychopathology: Concepts, issues, and research strategies. Journal of Child Psychology and Psychiatry, 32, 1063-1080.

Charney, D. (2004). Psychobiological mechanisms of resilience and vulnerability: Implications for successful adaptation to extreme stress. American Journal of Psychiatry, 161, 195-216.

Cicchetti, D. (2002a). How a child builds a brain: Insights from normality and psychopathology. In W. W. Hartup \& R. A. Weinberg (Eds.), Child psychology in retrospect and prospect: The Minnesota Symposia on Child Psychology (Vol. 32, pp. 23-71). Hillsdale, NJ: Erlbaum.

Cicchetti, D. (2002b). The impact of social experience on neurobiological systems: Illustration from a constructivist view of child maltreatment. Cognitive Development, 17, 1407-1428.

Cicchetti, D., \& Cannon, T. D. (1999). Neurodevelopmental processes in the ontogensis and epigenesis of psychopathology. Development and Psychopathology, 11, 375-393.

Cicchetti, D., \& Curtis, W. J. (2006). The developing brain and neural plasticity: Implications for normality, psychopathology, and resilience. In D. Cicchetti \& D. J. Cohen (Eds.), Developmental psychopathology: Vol. 2. Developmental neuroscience (2nd ed., pp. 1-64). Hoboken, NJ: Wiley.

Cicchetti, D., \& Curtis, W. J. (Eds.). (2007). A multilevel approach to resilience. Development and Psychopathology, 19, 627-955.

Cicchetti, D., \& Gunnar, M. R. (2008). Integrating biological measures into the design and evaluation of preventive intervention. Development and Psychopathology, 20, 737-743.

Cicchetti, D., \& Hinshaw, S. P. (Eds.). (2002). Prevention and intervention science: Contributions to developmental theory. Development and Psychopathology, 14, 667-981.

Cicchetti, D., \& Schneider-Rosen, K. (1986). An organizational approach to childhood depression. In M. Rutter, C. Izard, \& P. Read (Eds.), Depression in young people: Clinical and developmental perspectives ( $\mathrm{pp} .71-$ 134). New York: Guilford Press.

Cicchetti, D., \& Tucker, D. (1994). Development and self-regulatory structures of the mind. Development and Psychopathology, 6, 533-549.

Cole, D. A. (1990). Relation of social and academic competence to depressive symptoms in childhood. Journal of Abnormal Psychology, 99, 422-429.

Cole, D. A. (1991). Preliminary support for a competency-based model of depression in children. Journal of Abnormal Psychology, 100, 181-190.

Cole, D. A. (2006). Coping with longitudinal data in research on developmental psychopathology. International Journal of Behavioral Development, 30, 20-25.

Cole, D. A., Martin, J. M., Powers, B., \& Truglio, R. (1996). Modeling causal relations between academic and social competence and depression: A

multitrait-multimethod longitudinal study of children. Journal of Abnormal Psychology, 105, 258-270.

Cole, D. A., \& Maxwell, S. E. (2003). Testing mediational models with longitudinal data: Questions and tips in the use of structural equation modeling. Journal of Abnormal Psychology, 112, 558-577.

Colombo, J., Kannass, K. N., Shaddy, D. J., Kundurthi, S., Maikranz, J. M., Anderson, C. J., et al. (2004). Maternal DHA and the development of attention in infancy and toddlerhood. Child Development, 74, 1254-1267.

Conger, R. D., Neppl, T., Kim, K. J., \& Scaramella, L. (2003). Angry and aggressive behavior across three generations: A prospective, longitudinal study of parents and children. Journal of Abnormal Child Psychology, 31, 143-160.

Dishion, T. J., \& Patterson, G. R. (2006). The development and ecology of antisocial behavior in children and adolescents. In D. Cicchetti \& D. J. Cohen (Eds.), Developmental psychopathology (Vol. 3, 2nd ed., pp. 503-541). Hoboken, NJ: Wiley.

Dodge, K. A., Greenberg, M. T., Malone, P. S., \& The Conduct Problems Prevention Research Group. (2008). Testing an idealized dynamic cascade model of the development of serious violence in adolescence. Child Development, 79, 1907-1927.

Dodge, K. A., Malone, P., Lansford, J. E., Miller, S., Pettit, G. S., \& Bates, J. E. (2009). A dynamic cascade model of the development of substanceuse onset. Monographs of the Society for Research in Child Development, 74(Serial No. 294), 1-120.

Dodge, K. A., \& Pettit, G. S. (2003). A biopsychosocial model of the development of chronic conduct problems in adolescence. Developmental Psychology, 39, 349-371.

Ford, D. H., \& Lerner, R. M. (1992). Developmental systems theory: An integrative approach. Newbury Park, CA: Sage.

Fry, A. F., \& Hale, S. (1996). Processing speed, working memory, and fluid intelligence: Evidence for a developmental cascade. Psychological Science, 7, 237-241.

Gottlieb, G. (1998). The significance of biology for human development: A developmental psychobiological systems view. In W. Damon \& R. M. Lerner (Eds.), Handbook of child psychology (Vol. 1, 5th ed., pp. 233 273). New York: Wiley.

Gottlieb, G. (2007). Probabilistic epigenesis. Developmental Science, 10, $1-11$.

Gottman, J. M. (1993). A theory of marital dissolution and stability. Journal of Family Psychology, 7, 57-75.

Gunnar, M. R., \& Quevedo, K. (2007). The neurobiology of stress and development. Annual Review of Psychology, 58, 145-173.

Hanson, D. R., \& Gottesman, I. I. (2007). Choreographing genetic, epigenetic, and stochastic steps in the dances of developmental psychopathology. In A. S. Masten (Ed.), Multilevel dynamics in developmental psychopathology: Pathways to the future. Minnesota Symposia on Child Psychology (Vol. 34, pp. 27-43). Mahwah, NJ: Erlbaum.

Heckman, J. J. (2006). Skill formation and the economics of investing in disadvantaged children. Science, 312, 1900-1902.

Hinshaw, S. P. (1992). Externalizing behavior problems and academic underachievement in childhood and adolescence: Causal relationships and underlying mechanisms. Psychological Bulletin, 111, 127-155.

Hinshaw, S. P. (2002). Intervention research, theoretical mechanisms, and causal processes related to externalizing behavior problems. Development and Psychopathology, 14, 789-818.

Hinshaw, S. P., \& Anderson, C. A. (1996). Conduct and oppositional defiant disorders. In E. J. Mash \& R. A. Barkley (Eds.), Child psychopathology (pp. 113-149). New York: Guilford Press.

Järvinen-Pasley, A., Bellugi, U., Reilly, J., Mills, D. L., Galaburda, A., Reiss, A. L., et al. (2008). Defining the social phenotype in Williams syndrome: A model for linking gene, the brain, and behavior. Development and Psychopathology, 20, 1-35. 
Jensen, P. S. (2003). Comorbidity and child psychopathology: Recommendations for the next decade. Journal of Abnormal Child Psychology, 31, 293-300.

Kagan, J. (2005). Human morality and temperament. Nebraska Symposium on Motivation, 51, 1-32.

Kohlberg, L., LaCrosse, J., \& Ricks, D. (1972). The predictability of adult mental health from childhood behavior. In B. B. Wolman (Ed.), Manual of child psychopathology (pp. 1217-1284). New York: McGraw-Hill.

Lupien, S. J., Ouellet-Morin, I., Hupbach, A., Tu, M. T., Buss, C., Walker, D., et al. (2006). Beyond the stress concept: Allostatic load-A developmental biological and cognitive perspective. In D. Cicchetti \& D. Cohen (Eds.), Developmental psychopathology: Vol. 2. Developmental neuroscience (2nd ed., pp. 578-628). Hoboken, NJ: Wiley.

Masten, A. S., Burt, K. B., \& Coatsworth, J. D. (2006). Competence and psychopathology in development. In D. Cicchetti \& D. J. Cohen (Eds.), Developmental psychopathology (Vol. 3, 2nd ed., pp. 696-738). Hoboken, NJ: Wiley.

Masten, A. S., \& Coatsworth, J. D. (1998). The development of competence in favorable and unfavorable environments: Lessons from research on successful children. American Psychologist, 53, 205-220.

Masten, A. S., Long, J. D., Kuo, S. I.-C., McCormick, C. M., \& Desjardins, C. D. (2009). Developmental models of strategic intervention. European Journal of Developmental Science, 3, 282-291.

Masten, A. S., Roisman, G. I., Long, J. D., Burt, K. B., Obradovic, J., Riley, J. R., et al. (2005). Developmental cascades: Linking academic achievement and externalizing and internalizing symptoms over 20 years. Developmental Psychology, 41, 733-746.

Masten, A. S., \& Wright, M. O. (2009). Resilience over the lifespan: Developmental perspectives on resistance, recovery, and transformation. In J. W. Reich, A. J. Zautra, \& J. S. Hall (Eds.), Handbook of adult resilience (pp. 213-237). New York: Guilford Press.

McEwen, B. S., \& Stellar, E. (1993). Stress and the individual mechanisms leading to disease. Archives of Internal Medicine, 153, 2093-2101.

Meaney, M. J. (2010). Epigenetics and the biological definition of Gene $\times$ Environment interactions. Child Development, 81, 41-79.

Obradović, J., Burt, K. B., \& Masten, A. S. (2010). Testing a dual cascade model linking competence and symptoms over 20 years from childhood to adulthood. Journal of Clinical Child and Adolescent Psychology, 39, 90-102.

Patterson, G. R., DeBaryshe, B. D., \& Ramsey, E. (1989). A developmental perspective on antisocial behavior. American Psychologist, 44, 239-335.
Patterson, G. R., Reid, J. B., \& Dishion, T. J. (1992). A social interactional approach: Vol. 4. Antisocial boys. Eugene, OR: Castaglia.

Patterson, G. R., \& Stoolmiller, M. (1991). Replications of a dual failure model for boys' depressed mood. Journal of Consulting and Clinical Psychology, 59, 491-498.

Reynolds, A. J., \& Temple, J. A. (2006). Economic benefits of investments in preschool education. In E. Zigler, W. Gilliam, \& S. Jones (Eds.), A vision for universal prekindergarten (pp. 37-68). New York: Cambridge University Press.

Roisman, G. I., Masten, A. S., Coatsworth, J. D., \& Tellegen, A. (2004). Salient and emerging developmental tasks in the transition to adulthood. Child Development, 75, 1-11.

Rutter, M. (1999). Resilience concepts and findings: Implications for family therapy. Journal of Family Therapy, 21, 119-144.

Rutter, M., Kim-Cohen, J., \& Maughan, B. (2006). Continuities and discontinuities in psychopathology between childhood and adult life. Journal of Child Psychology and Psychiatry, 47, 276-295.

Rutter, M., \& Sroufe, L. A. (2000). Developmental psychopathology: Concepts and challenges. Development and Psychopathology, 12, 265-296.

Sameroff, A. J. (2000). Developmental systems and psychopathology. Development and Psychopathology, 12, 297-312.

Serbin, L. A., \& Karp, J. (2004). The intergenerational transfer of psychosocial risk: Mediators of vulnerability and resilience. Annual Review of Psychology, 55, 333-363.

Shaffer, A., Burt, K. B., Obradovic, J., Herbers, J. E., \& Masten, A. S. (2009). Intergenerational continuity in parenting quality: The mediating role of social competence. Developmental Psychology, 45, 1227-1240.

Shonkoff, J. P., Boyce, W. T., \& McEwen, B. S. (2009). Neuroscience, molecular biology, and the childhood roots of health disparities. Journal of the American Medical Association, 301, 2252-2259.

Sroufe, L. A. (1979). The coherence of individual development: Early care, attachment, and subsequent developmental issues. American Psychologist, 34, 834-841.

Thelen, E., \& Smith, L. (1998). Dynamic systems theories. In W. Damon (Series Ed. \& Vol. Ed.), Handbook of child psychology: Vol. 1. Theore tical models of human development (5th ed., pp. 563-634). New York: Wiley.

Ward, M. (1995). Butterflies and bifurcations: Can chaos theory contribute to our understanding of family systems? Journal of Marriage and the Family, 57, 629-638. 